\title{
Flame behavior from an opening at different elevations on the facade wall of a fire compartment
}

Lu, K., Wang, Z., Ding, Y., Wang, J., Zhang, J., Delichatsios, M., \& Hu, L. (2020). Flame behavior from an opening at different elevations on the facade wall of a fire compartment. Proceedings of the Combustion Institute, 38(3), 4551-4559. https://doi.org/10.1016/j.proci.2020.07.094

Link to publication record in Ulster University Research Portal

\section{Published in:}

Proceedings of the Combustion Institute

\section{Publication Status:}

Published online: 22/09/2020

DOI:

10.1016/j.proci.2020.07.094

\section{Document Version}

Author Accepted version

\section{General rights}

Copyright for the publications made accessible via Ulster University's Research Portal is retained by the author(s) and / or other copyright owners and it is a condition of accessing these publications that users recognise and abide by the legal requirements associated with these rights.

\section{Take down policy}

The Research Portal is Ulster University's institutional repository that provides access to Ulster's research outputs. Every effort has been made to ensure that content in the Research Portal does not infringe any person's rights, or applicable UK laws. If you discover content in the Research Portal that you believe breaches copyright or violates any law, please contact pure-support@ulster.ac.uk. 


\title{
Flame behavior from an opening at different elevations on the facade wall of a fire compartment
}

\author{
Kaihua Lu ${ }^{\mathrm{a}}$, Zichang Wang ${ }^{\mathrm{a}}$, Yanming Ding ${ }^{\mathrm{a}}$, Jie Wang ${ }^{\mathrm{d}}$, Jianping Zhang ${ }^{\mathrm{e}}$, \\ Michael A. Delichatsios ${ }^{b, c}$, Longhua $\mathrm{Hu}^{\mathrm{b}^{*}}$ \\ ${ }^{\text {a }}$ Faculty of Engineering, \\ China University of Geosciences (Wuhan), Wuhan, Hubei, 430074, China \\ ${ }^{\mathrm{b}}$ State Key Laboratory of Fire Science, \\ University of Science and Technology of China, Hefei, Anhui, 230026, China \\ ${ }^{\mathrm{c}}$ Northeastern University, Boston, MA, 02115, USA \\ ${ }^{\mathrm{d}}$ School of Resource and Environmental Engineering, \\ Wuhan University of Science and Technology, Wuhan, Hubei, 430081, China
}

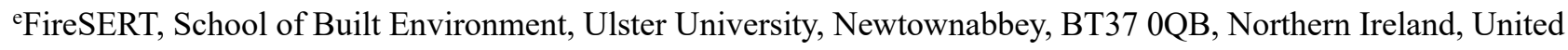
Kingdom

Colloquium: Fire Research

*Corresponding author:

Tel: +86 (0) 551-63606446; Fax: +86 (0) 551-63601669; Email address: hlh@ustc.edu.cn;

Postal address: State Key Laboratory of Fire Science, University of Science and Technology of China, Hefei, Anhui, 230026, China

Word Count (6122 words): Main text 2784 (Introduction 554; Experimental 377; Results 1525; Conclusion 313; Acknowledgement 15); Equations 175; References 594; Table 190; Figures and Captions 2379 (Fig. 1 334; Fig. 2 270; Fig. 3 352; Fig. 4 637; Fig. 5 290; Fig. 6 162; Fig. 7 167; Fig. 8 167). 


\section{Abstract}

This paper investigates flame ejected from opening at different elevations on the facade wall of a fire compartment. Two reduced-scale experimental models are employed consisting of a cubic fire compartment with one opening and a vertical facade wall. Experiments are conducted by varying the height of the opening and at different heat release rates (HRRs). Results show that the distance of the flame base from the bottom of the opening gradually decreases with increasing opening elevation. The external flame height measured from its base increases firstly, reaches the maximum when the opening is located at approximately half height of the fire compartment and subsequently decreases as the opening moves up. Moreover, the increasing elevation of the opening contributes to decreasing mean critical HRR for flame ejection. The above observations are found to be due to the increased deep sinking of the cold inflow while it is mixing and reacting with hot gases, as the vertical elevation of the opening increases, as supported by the additional computational fluid dynamics (CFD) simulation results. This is an important new observation, because whilst having an opening at elevated locations is common in a compartment fire, it has not been accounted for in previous classic models on ejected flame behavior from opening of a fire compartment. By identifying the similarities and differences of facade flame dynamics as the vertical elevation of the opening varies, a new model is proposed and validated for flame height with characteristic length scales to account for the changes in air inflow and critical heat release rate for flame ejection with opening elevations.

Keywords: Compartment fire; opening elevation; temperature; flame base; facade flame height. 


\section{Introduction}

Following research by Yokoi [1] in 1960, numerous studies have addressed the issue of facade flames ejected from an opening (such as a window or a door) from room fires in buildings. Much attention has been drawn over last ten years [2-10] on several key parameters including gas temperature profiles [11-13], facade flame heights $[14,15]$ as well as heat flux/radiation intensity $[11-13,16,17]$.

Recently, a non-dimensional model on facade flame height has been established by Lee et al. [18], which is based on the physics that the facade flame develops as the result of the unburned (excess) fuel ejected through the opening, then further burned outside the opening. Based on the assumption that the flow condition inside the compartment is well-mixed and uniform, similarity analysis is performed and a classic relation was proposed for the ejected flame height $\left(Z_{f}\right)$ [18-20]:

$$
\begin{gathered}
\frac{Z_{f}}{\ell_{1}}=f c n\left(\dot{Q}_{e x}^{*}\right)=f c n\left(\frac{\dot{Q}_{e x}}{\rho_{\infty} C_{p} T_{\infty} \sqrt{g} \ell_{1}^{5 / 2}}\right)=f c n\left(\frac{\dot{Q}-1500 A \sqrt{H}}{\rho_{\infty} C_{p} T_{\infty} \sqrt{g} \ell_{1}^{5 / 2}}\right) \\
\ell_{1}=(A \sqrt{H})^{2 / 5}
\end{gathered}
$$

where the dimensionless excess heat release rate (HRR) $\dot{Q}_{e x}^{*}$ is defined in terms of the excess HRR $\dot{Q}_{e x}$ (the difference between the total HRR $\dot{Q}$ and HRR inside the compartment for under-ventilated fires $\dot{Q}_{\text {inside }}=1500 A \sqrt{H} \mathrm{~kW}$ ) and the characteristic length scale representing the opening dimensions $\ell_{1}$ (A and $H$ are the area $\left(\mathrm{m}^{2}\right)$ and height $(\mathrm{m})$, respectively). In addition, Lee [20] depicts the facade flame as a fire standing at the neutral plane of the opening with HRR of $\dot{Q}_{e x}$ generated by a rectangular source having two characteristic length scales $\ell_{1}$ (representing the window dimension, parallel to facade wall, reflecting physically the opening condition affecting the convection of outflow $[18,20]$ ) and $\ell_{2}$ (representing the flame horizontal extension outside the opening, normal to facade wall, reflecting physically the competition of outflow horizontal momentum to buoyance flux $[9,18$, 20]). $\ell_{2}$ is a function as: 


$$
\ell_{2}=\left(1-h_{1} / H\right)^{3 / 4} \cdot\left(A H^{2}\right)^{1 / 4}
$$

in which $h_{1}$ is the neutral plane level above opening bottom, usually regarded as $0.4 H$ [e.g., 18-21]. It was also verified that the temperature inside the compartment is spatially uniform, determined by the HRR inside the compartment and the heat losses to the wall [21]:

$$
\Delta T_{g}=\frac{1500 A \sqrt{H} / A_{T}}{h_{c}+0.5 C_{p} A \sqrt{H} / A_{T}}
$$

where $\Delta T_{g}$ is the temperature rise, $h_{c}$ is convection coefficient (around $0.0183 \mathrm{~W} /\left(\mathrm{m}^{2} \mathrm{~K}\right)$ ), and the parameter $A \sqrt{H} / A_{T}$ is the opening factor defined as the ratio of the ventilation factor $A \sqrt{H}$ (reflecting the maximum heat release rate $1500 A \sqrt{H}$ inside the compartment) to the total exposure surface area of fire compartment (exclude the area of the opening) $A_{T} \quad\left(A_{T}=6 L^{2}-H W\right.$, reflecting the total heat loss through wall $h_{c} A_{T} \Delta T$ ). In addition, other studies [22-26] focused on different situations and boundary conditions (such as a facing wall [22], eaves [23], side walls [24], ambient pressure [25] and merging behavior for double openings [14, 26]). However, in all previous studies, the elevation of the opening mainly remained at the center of the fire compartment. In many practical situations, the elevation of the opening can vary but this effect has not been well quantified yet. In this work, we will investigate systemically the effects of the vertical elevation of the opening on the resulting facade flame behavior.

Experiments are performed and analyzed using two sets of reduced-scale cubic compartments and varying opening elevations on the facade wall. The temperature inside the fire compartment, the position of the flame base and the external flame height on the facade are measured. The details of the experiments are described in the second section, followed by the experimental results, discussions and non-dimensional analysis. Finally, the major findings of this work are summarized. 


\section{Experimental setup}

Experiments were conducted in two sets of cubic compartment, Compartment A (1:4) and Compartment B (1:2), respectively. Figure 1 illustrates the setup of Compartment A, with a vertical facade wall of $5 \mathrm{~m}(\mathrm{H}) \times 3 \mathrm{~m}(\mathrm{~W})$. Compartment A was inner-lined with $5 \mathrm{~cm}$ thick ceramic fiberboards (mainly consist of $\mathrm{SiO}_{2}$ and $\mathrm{Al}_{2} \mathrm{O}_{3}$ ), with the density, thermal conductivity and specific heat about 280 $\mathrm{kg} / \mathrm{m}^{3}, 0.13 \mathrm{~W} / \mathrm{mK}$ and $0.9 \mathrm{~kJ} / \mathrm{kgK}$ respectively. A square opening $(0.25 \mathrm{~m} \times 0.25 \mathrm{~m} ; 0.30 \mathrm{~m} \times 0.30 \mathrm{~m})$ was set on the centerline of the facade. A similar configuration was applied for Compartment B, except for that the inner-lining material was $7.5 \mathrm{~cm}$ thick while the opening of $0.50 \mathrm{~m} \times 0.50 \mathrm{~m}$ and $0.60 \mathrm{~m} \times$ $0.60 \mathrm{~m}$ was employed. These opening sizes are representative of a window of size 1-1.2 m practically based on the scaling law. Note that the ventilation factor $A \sqrt{H}$ differs significantly for these opening sizes. Different opening elevations were examined: (a) bottom group; (b) lower group; (c) center group; (d) upper group and (e) top group as listed in Table 1. Practically, when the opening is located at the bottom, it can be regarded as a door, whereas at different elevations it simulates a window or vent.

To eliminating the complex effect of heat feedback from the flame to the condensed fuel burning $[27,28]$, gaseous fuel, LPG (Liquefied Petroleum Gas, heat of combustion $=50400 \mathrm{~kJ} / \mathrm{kg}$ ), is supplied with a constant low rate (controlled by a flow meter) into a square porous gas burner flush on the floor at the center of the compartment. The total HRR is estimated with a combustion efficiency of 0.9 [18]. Four K-type thermocouples of $0.5 \mathrm{~mm}$ (uncertainty $\pm 1^{\circ} \mathrm{C}$ ) are installed inside Compartment $\mathrm{A}$ at the inner- and outer corners ( $5 \mathrm{~cm}$ to side walls, and $0.2 \mathrm{~m}, 0.4 \mathrm{~m}$ below ceiling). The experiments are ensured to reach steady state (although with small time-fluctuation) as indicated by temperature history (Fig.1). The flame base position at the opening and the flame height are recorded by a CCD 
camera (25 fps) at the steady state and acquired through OTSU method [29] (uncertainty \pm 1 pixel $\approx \pm$ $0.5 \%$ of flame height). The experiments are carried out 3 times to ensure the repeatability.

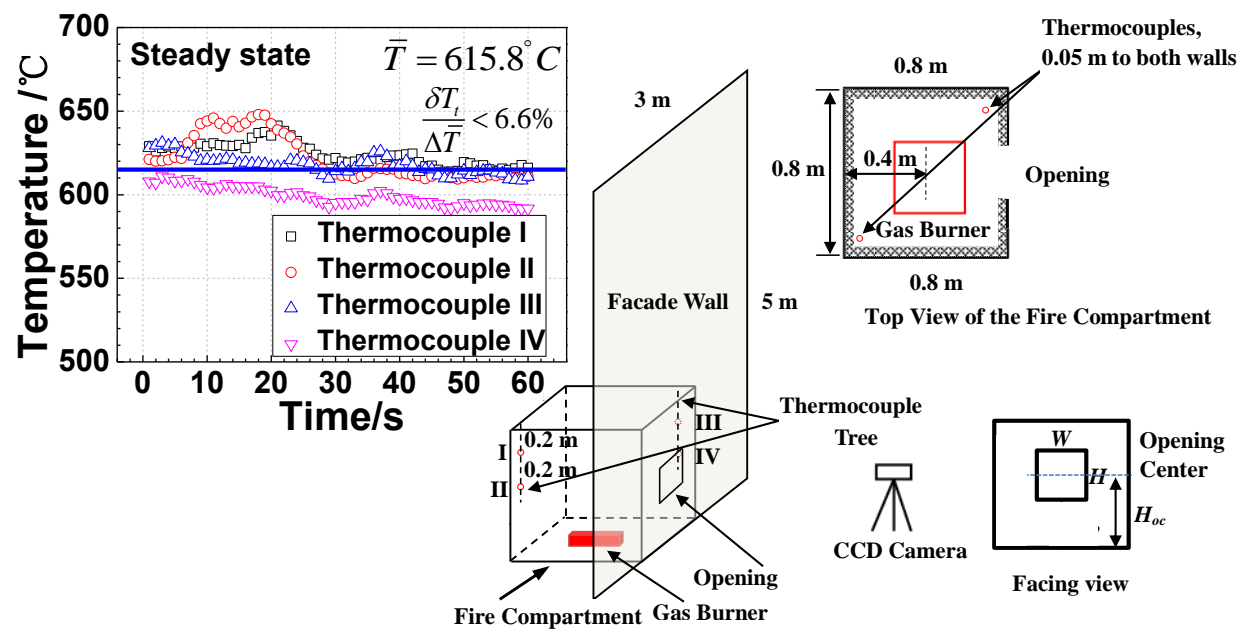

Fig. 1 Experimental setup

Table1. Summary of experimental scenarios

\begin{tabular}{|c|c|c|c|c|c|c|c|c|c|c|c|c|c|}
\hline \multirow{4}{*}{$\begin{array}{c}\mathbf{A} \\
\text { Top }\end{array}$} & \multicolumn{2}{|c|}{ Opening size } & \multirow{3}{*}{$\begin{array}{c}\text { Opening center } \\
\text { elevation } \boldsymbol{H}_{\mathbf{o c}} / \mathbf{m}\end{array}$} & \multirow{2}{*}{\multicolumn{10}{|c|}{ Total heat release rate/kW }} \\
\hline & \multirow{2}{*}{$\begin{array}{l}H / \mathrm{m} \\
0.25 \\
\end{array}$} & \multirow{2}{*}{$\frac{W / \mathrm{m}}{0.25}$} & & & & & & & & & & & \\
\hline & & & & \multicolumn{2}{|c|}{129} & \multicolumn{2}{|c|}{137} & \multicolumn{2}{|c|}{146} & \multicolumn{2}{|c|}{155} & \multicolumn{2}{|c|}{164} \\
\hline & 0.3 & 0.3 & 0.55 & \multicolumn{2}{|c|}{146} & \multicolumn{2}{|c|}{155} & \multicolumn{2}{|c|}{164} & \multicolumn{2}{|c|}{173} & \multicolumn{2}{|c|}{182} \\
\hline \multirow{2}{*}{ Upper } & 0.25 & 0.25 & 0.465 & \multicolumn{2}{|c|}{129} & \multicolumn{2}{|c|}{137} & \multicolumn{2}{|c|}{146} & \multicolumn{2}{|c|}{155} & \multicolumn{2}{|c|}{164} \\
\hline & 0.3 & 0.3 & 0.46 & \multicolumn{2}{|c|}{146} & \multicolumn{2}{|c|}{155} & \multicolumn{2}{|c|}{164} & \multicolumn{2}{|c|}{173} & \multicolumn{2}{|c|}{182} \\
\hline \multirow{2}{*}{ Center } & 0.25 & 0.25 & 0.35 & \multicolumn{2}{|c|}{129} & \multicolumn{2}{|c|}{137} & \multicolumn{2}{|c|}{146} & & & & \\
\hline & 0.3 & 0.3 & 0.35 & & & & & & & & & & \\
\hline I & 0.25 & 0.25 & 0.245 & & & & & & & & & & \\
\hline Lower & 0.3 & 0.3 & 0.23 & & & & & & & & & & \\
\hline Pottom & 0.25 & 0.25 & 0.125 & & & & & & & & & & \\
\hline Bottom & 0.3 & 0.3 & 0.15 & & & & & & & & & & \\
\hline B & Openi & size & Opening center & & & & Tata & $x$ & ace r & & & & \\
\hline D & $H / \mathrm{m}$ & $W / \mathrm{m}$ & elevation $H_{\mathrm{oc}} / \mathrm{m}$ & & & & lota & ICat & ase & $\mathbf{e} / \mathbf{K} \mathbf{V}$ & & & \\
\hline Ton & 0.5 & 0.5 & 1.10 & 332 & 384 & 409 & 435 & 460 & 476 & 491 & 506 & 522 & 555 \\
\hline $10 \mathrm{p}$ & 0.6 & 0.6 & 1.05 & 432 & 458 & 488 & 514 & 529 & 547 & 563 & I & I & I \\
\hline Tom & 0.5 & 0.5 & 0.89 & 384 & 409 & 435 & 460 & 476 & 491 & 506 & 522 & 563 & I \\
\hline upper & 0.6 & 0.6 & 0.86 & 432 & 460 & 476 & 499 & 511 & 527 & 565 & 1 & I & 1 \\
\hline Center & 0.5 & 0.5 & 0.675 & 384 & 409 & 435 & 460 & 476 & 491 & 506 & 522 & I & 1 \\
\hline center & 0.6 & 0.6 & 0.675 & 450 & 476 & 491 & 509 & 524 & 540 & 557 & 1 & I & 1 \\
\hline I & 0.5 & 0.5 & 0.46 & 384 & 409 & 435 & 450 & 465 & 481 & 496 & 617 & 1 & 1 \\
\hline Lower & 0.6 & 0.6 & 0.49 & 532 & 547 & 568 & 580 & 596 & 660 & I & 1 & I & 1 \\
\hline
\end{tabular}




\section{Experimental results and analysis}

\subsection{Experimental results}

Figure 2 shows that the average temperature inside the compartment for Compartment A, indicating a considerable increase and then decrease as the opening moves up on the compartment wall. The experimental values are similar to the predictions by Eq. (4) shown also for reference on the right-axis of this figure.

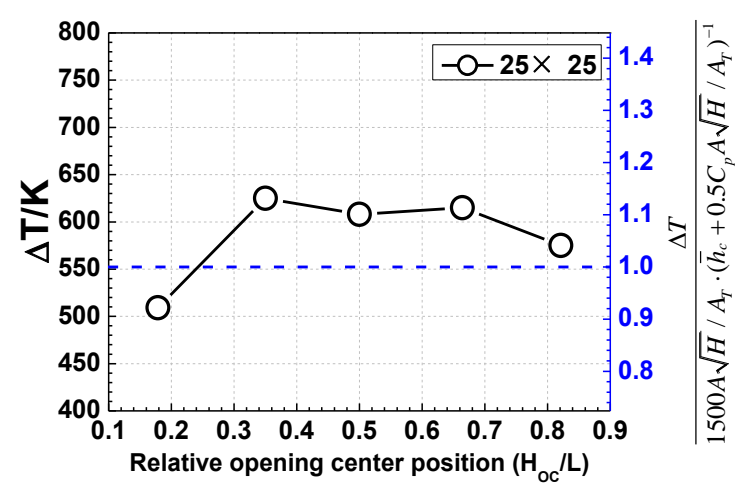

(a) $25 \mathrm{~cm} \times 25 \mathrm{~cm}$

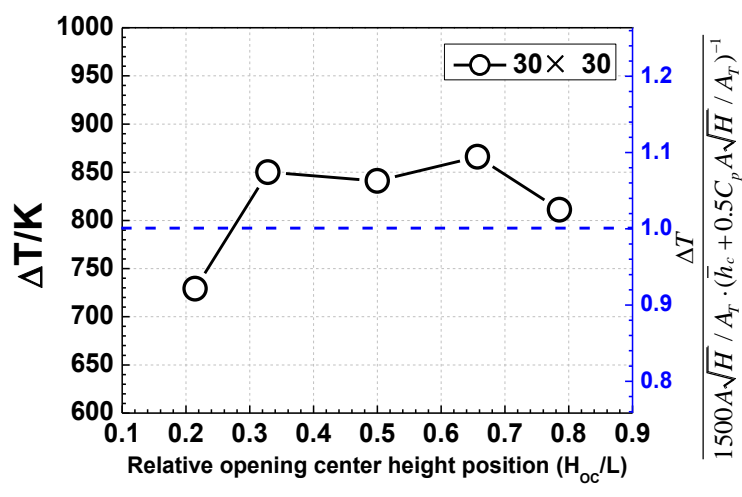

(b) $30 \mathrm{~cm} \times 30 \mathrm{~cm}$

Fig. 2 Gas temperature rise inside the fire compartment for different opening elevations

Figure 3 plots the facade flame height against the dimensionless height $H_{o c} / L$ for both compartments ( $L$ : compartment internal height, i.e. $0.7 \mathrm{~m}$ for Compartment $\mathrm{A}$ and $1.35 \mathrm{~m}$ for Compartment B). The mean flame heights were obtained [29] at 50\% intermittency [30-32] of the luminance intensity recorded by the CCD camera. The facade flame height also increases initially and then decreases as the opening moves up. The flame height is highest when the opening is located at approximately half height of the fire compartment. 


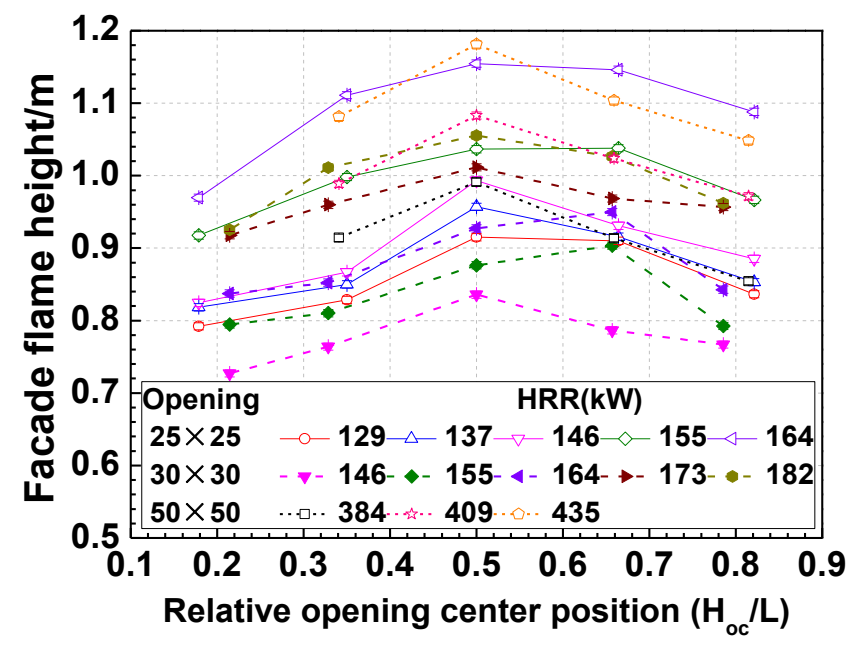

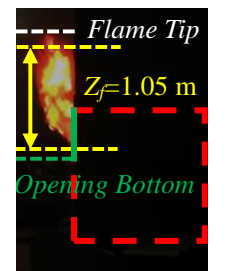

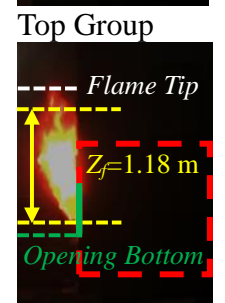

Center Group Compartment B, 435 kW

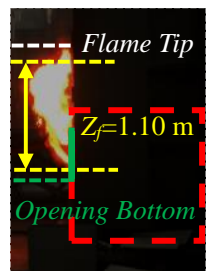

Upper Group

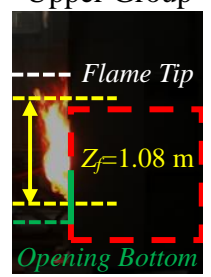

Lower Group

Fig. 3 Facade flame heights from the flame base level show to first increase then decrease with rising of the opening elevation.

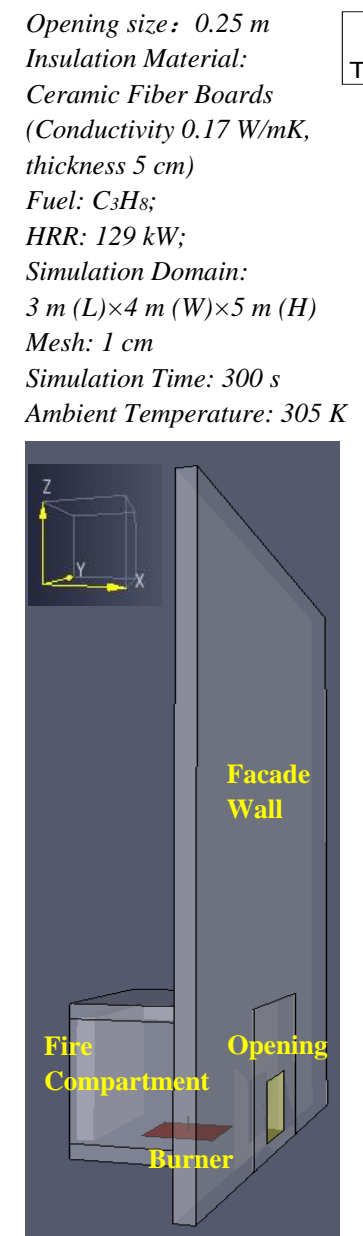

FDS model

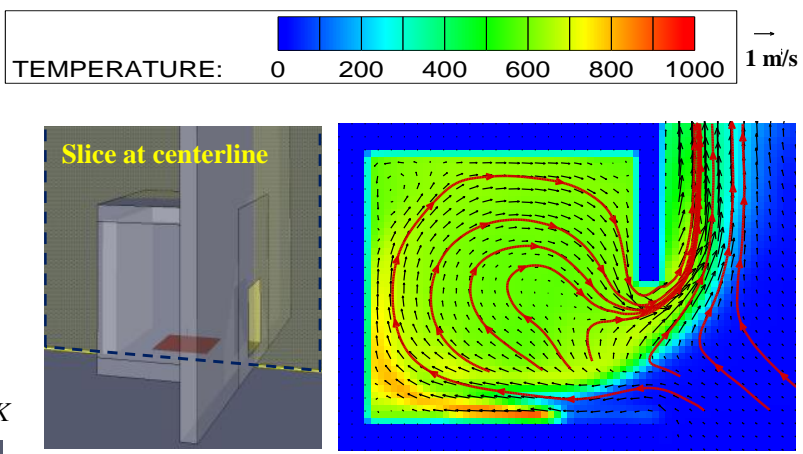

Bottom group
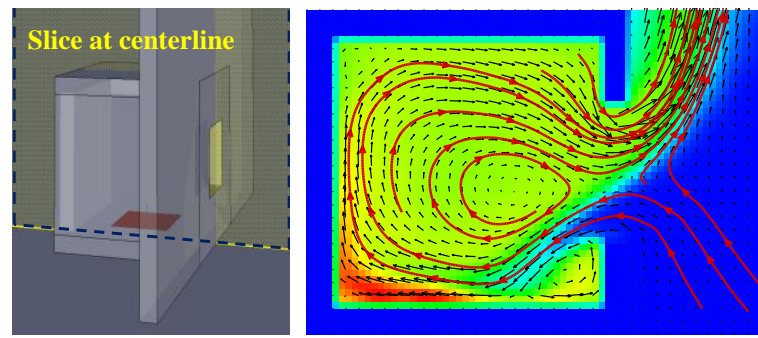

Center group
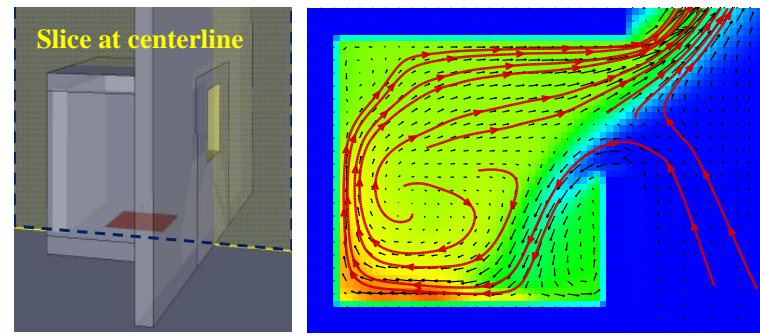

Top group

Fig. 4 An illustration of the flow pattern for different elevations of opening on the facade simulated by FDS (Compartment A)

CFD simulation employing FDS (Fire Dynamic Simulator with Large Eddy Simulation (LES) in 
turbulence simulation, infinitely fast reaction in combustion and Gray gas radiation with finite volume solution in radiation models) was performed (Fig. 4) showing the complex flow field at the opening and that inside the compartment, which helps interpreting the physical mechanism. It is seen that the above change in flame height is shown to be due to the different sinking down behavior of hot gases or cold fresh air inside the compartment with opening of different elevations (opening at top, center and bottom positions for comparison). We can see that the temperature is not uniform, especially at the vicinity of the opening as a result of the mixing of inflow fresh air with hot gases inside the compartment near the opening. This attributes to a major difference observed in the flow structures. For the bottom group, the hot gases (a mixture of fresh air and fuel) firstly go up and then sink deeper to be ejected from the opening compared with that of the center group. In comparison, when the opening is at a higher location, the fresh air firstly sinks deeper to reach the burner surface, and then the hot gases exit relatively more easily at the top of the opening. Meanwhile, the horizontal momentum of outflow seems to be stronger, which is evidenced by relatively larger horizontal projection of the outflow as the opening moves up. This indicates that the characteristic length scale $\ell_{2}$ could change as a result of the different opening elevations and hence flow patterns. Note that $\ell_{2}$ is a characteristic length scale representing the competition of horizontal momentum to the upward buoyancy flux of the outflow at the opening. The change in the characteristic length scale $\ell_{2}$ will be experimentally represented by acquiring the flame base positions in the following section.

The height of flame base measured above the opening bottom is shown in Fig. 5. The location of flame base at the opening could be interpreted as the neutral plane where there is no pressure difference, i.e. $Z_{0} \sim h_{1}$. It appears nearly constant for various HRRs and at a given opening elevation (i.e. bottom, lower, center, higher and top). The flame base location normalized by the opening height is plotted in 
Fig. 6 against the location of the opening normalized by the internal height of the compartment, which shows a good linear correlation. When the opening moves up, this flame base lowers down. This is due to, as shown in Fig. 4, the mixing of the cold inflow air (with a downward "sinking" effect) owing to its relatively higher density with the hot gases near the opening after it enters the compartment.

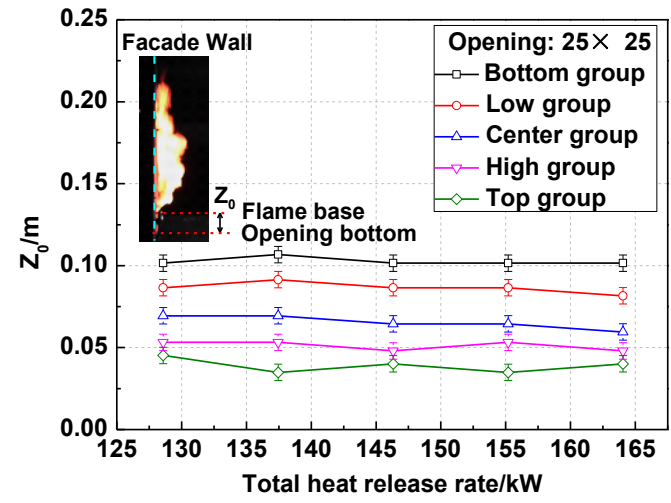

(a) $25 \mathrm{~cm} \times 25 \mathrm{~cm}$

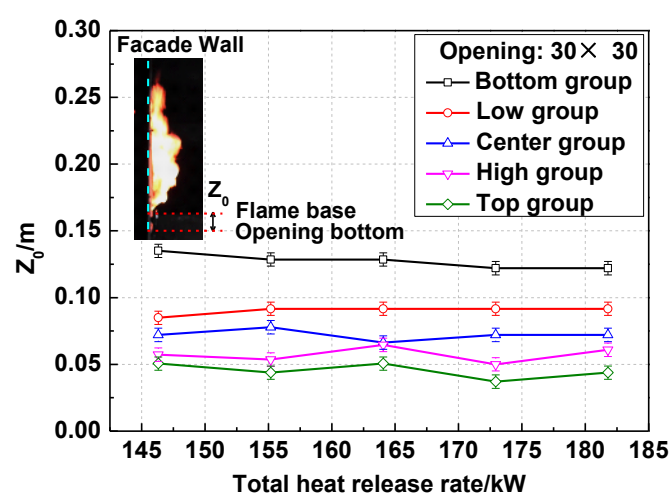

(b) $30 \mathrm{~cm} \times 30 \mathrm{~cm}$

Fig. 5 Flame base location above the opening bottom does not change with the HRR but it changes with the elevation of the opening

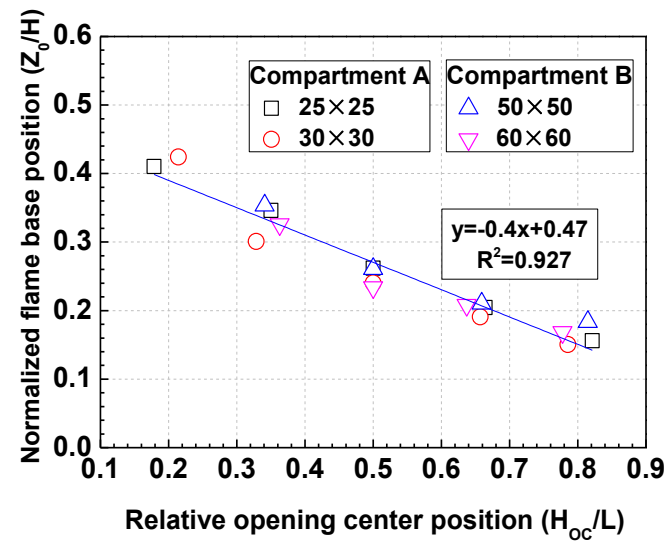

Fig. 6 Normalized flame base location for different opening elevation showing it decreases

\section{linearly with increasing of opening elevation}

The above variations in temperature, flow structure and the flame base (or neutral plane level) indicate that the critical HRR for flame ejection, which was considered to be constant as $\dot{Q}_{\text {inside }}=1500 A \sqrt{H} \mathrm{~kW}$, may have changed with the change of opening elevation. Considering the intermittent flame ejection nature, a mean HRR $\dot{Q}_{\text {intermittent,mean }}$ where the flame ejection probability is $50 \%$ was defined and for the present experiments $\left(\dot{Q}_{\text {intermittent,mean }} \approx\left(\dot{Q}_{\text {critical low }}+\dot{Q}_{\text {critical,high }}\right) / 2,[30]\right)$. 
Figure 7 presents $\dot{Q}_{\text {intermittent,mean }}$ normalized by $1500 A \sqrt{H}$ against the elevation of the opening center (height from the bottom of the compartment) divided by the height of the compartment. The results show that the normalized critical HRR also decreases as the opening moves up, which should be attributed to the fact of less fresh air flowing in (flame base drops down) hence more unburnt fuel ejecting out as discussed above.

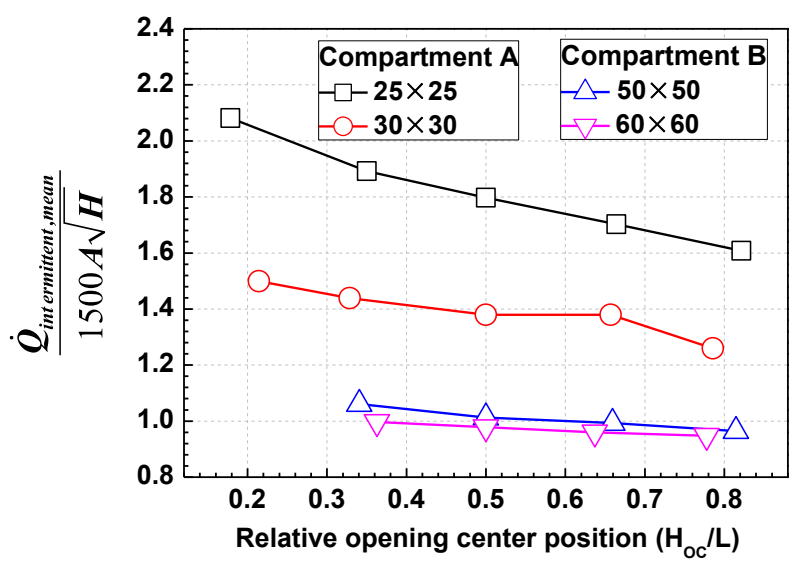

Fig. 7 The mean (i.e. 50\% probability) HRR for flame ejection normalized by HRR inside the compartment at different opening elevations

\subsection{A new model for flame height with both characteristic length scales $\left(\ell_{1}, \ell_{2}\right)$ to account for different opening elevations}

The above results suggest that the variation of the flame height for different opening elevation should be related to the change of physical mechanism behind the flame ejection behavior (including the variations of the flame base and the mean intermittent HRR, as a result of the change of the inflow and outflow conditions). For a lower opening elevation case, the flame base from the opening bottom is higher indicating more air incoming through the opening, and it is easier to reach the fire source; so the excess fuel would be relative less resulting in a relative lower flame height. When the opening moves up, the neutral plane level (distance from opening bottom to flame base) decreases which reduces the air incoming area; and as a result the inflow rate of the fresh air decreases resulting in a 
decrease of the $\dot{Q}_{\text {intermittent,mean }}$, implying that the flame is ejected more frequently or "more easily". The inflow fresh air has to sink down (also the interface of inflow and outflow becomes more tilted inside the compartment), counteracting the buoyancy inside the compartment, for a certain vertical distance to reach the fire source. That is, the inflow fresh air is relatively more difficult to reach the fire source to react with the fuel. All these will result in that more excess fuel is ejected, which could lead to a larger flame height. However, on the other hand, we should also notice that the characteristic length scale $\ell_{2}$, describing the competition of horizontal momentum and vertical buoyancy flux of ejected flames, would be increased when the opening moves up (based on Eq. 3 as the neutral plane level decreases, which is also well indicated by the flow pattern shown in Fig. 4), illustrating that the horizontal momentum becomes stronger and as a result the flame height is reduced. It is the competition of above two competing mechanisms that determines that the flame height firstly increases and then decreases as observed in the experiments (Fig. 3).

According to Delichatsios and Lee's theory $[18,20]$, the ejected flame outside the opening can be regarded as a rectangular fire source with side dimensions $\ell_{1}$ (parallel to facade) by $\ell_{2}$ (normal to facade) producing a heat release rate of $\dot{Q}_{e x}$. Therefore the flame height can be expressed as follows:

$$
\dot{Q}_{\text {ex }}\left(=\dot{Q}-\dot{Q}_{\text {inside }}\right) \propto \sqrt{g Z_{f}}\left[\alpha\left(\ell_{1}+2 \ell_{2}\right) Z_{f}+Z_{f}^{2}\right]
$$

The LHS of Eq. 5 represents the excess HRR, reflecting required fresh air for completing the combustion, which should be proportional to the air entrainment (RHS). On the RHS of Eq. 5, the $\sqrt{g Z_{f}}$ is the characteristic buoyancy-induced velocity at the flame tip, which represents the air entrainment velocity of the flame as it is usually taken as proportional to $\sqrt{g Z_{f}} ;\left(\ell_{1}+2 \ell_{2}\right) Z_{f}$ is a two-dimensional characteristic flame surface for air entrainment (with the perimeter of the rectangular 
$\left.\ell_{1}+2 \ell_{2}\right)$ and $Z_{f}^{2}$ is a three-dimensional characteristic flame surface for air entrainment. One notes that when flame height is relatively small, the RHS of Eq. (5) can be simplified as $\sim Z_{f}^{3 / 2}$; and when flame height is relatively larger, the RHS of Eq. (5) can be simplified as $\sim Z_{f}^{5 / 2}$. These simplifications are consistent with previous observations that $Z_{f} \sim \dot{Q}_{e x}^{2 / 3}$ when the excess heat release rate is relatively small as the flame behaves similarly to a two-dimensional "wall fire"; meanwhile $Z_{f} \sim \dot{Q}_{e x}^{2 / 5}$ when the excess heat release rate is relatively large as the flame behaves similarly to a three-dimensional "half axisymmetric fire". As we discussed earlier, $\dot{Q}_{\text {intermittent,mean }}$ changes with opening elevation, and thus, the replacement of $\dot{Q}_{\text {inside }}=1500 A \sqrt{H}$ with $\dot{Q}_{\text {intermittent,mean }}$ in Eq. 6 is one more step forward of Eq. 5 to include the effect indicated in Fig. 7. Here the length scale $\ell_{2}$ is more important than $\ell_{1}$ because $\ell_{1}$ is constant but $\ell_{2}$ is increased when the opening moves up that the flame height decreases (see Figs. 5-6, when the opening moves up, the flame base or neutral plane level $h_{1}$ decreases therefore $\ell_{2}$ increases based on Eq. 3). To unify the physical dimensions of both sides, the equation is rewritten as:

$$
\left(\dot{Q}-\dot{Q}_{\text {int ermittent,mean }}\right) /\left(\rho_{\infty} C_{p} T_{\infty} \sqrt{g}\right) \propto \sqrt{Z_{f}}\left[\alpha\left(\ell_{1}+2 \ell_{2}\right) Z_{f}+Z_{f}^{2}\right]
$$

We note that the constant $\alpha$ should be well chosen to satisfy the proportional relation between both sides. Applying $\alpha=2.7$, all experimental data are well correlated as shown in Fig. 8 by a linear function with the correlation coefficient $\mathrm{R}^{2}=0.968$. Some deviation is noticed for the slopes of Compartment $\mathrm{A}$ and B. A possible explanation is that the small difference in heat loss through the wall boundary would result in the change of the horizontal convective buoyancy strength of the outflow through the opening, which in turn affects the flame height. It could be a potential future work to explore the correlation for more opening dimensions and compartment scales.

Eq. (6) can be further rewritten as: 


$$
\sqrt{Z_{f}}\left[\alpha\left(\ell_{1}+2 \ell_{2}\right) Z_{f}+Z_{f}^{2}\right]=\Pi \cdot\left(\dot{Q}-\dot{Q}_{\text {intermittent,mean }}\right) /\left(\rho_{\infty} C_{p} T_{\infty} \sqrt{g}\right) \quad(\Pi=99.31)
$$

The expression can be transformed into a dimensionless way, as:

$$
\sqrt{Z_{f} / \ell_{2}}\left[(2 n+1) \alpha\left(Z_{f} / \ell_{2}\right)+n \cdot\left(Z_{f} / \ell_{2}\right)^{2}\right]=\Pi \cdot\left(\dot{Q}-\dot{Q}_{\text {intermittent,mean }}\right) /\left(\rho_{\infty} C_{p} T_{\infty} \sqrt{g}\right) \quad(\Pi=99.31)
$$

where $n=\frac{\ell_{2}}{\ell_{1}}$.

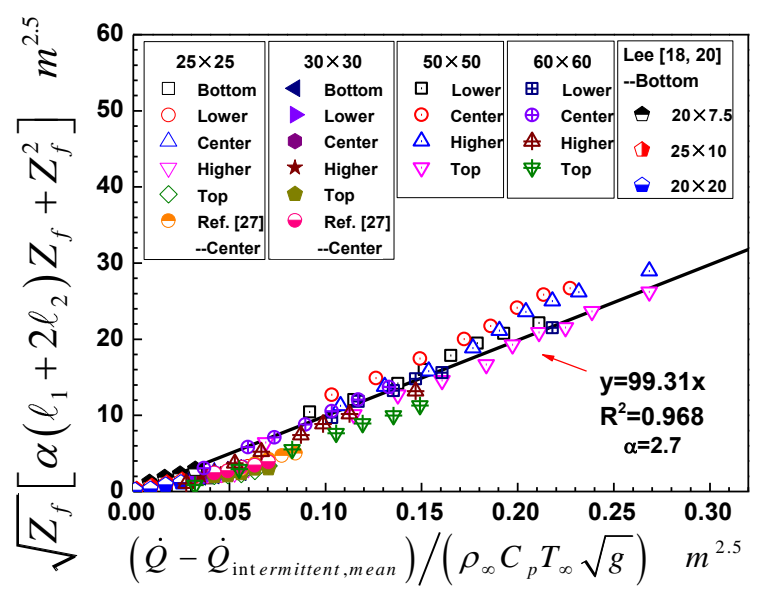

Fig. 8 A new model for flame height to account for the effect of opening elevations

\section{Conclusions}

This paper presents an experimental investigation of the flame ejecting behavior for different opening elevations on the facade of a fire compartment. Major findings are:

(1) Gas temperature inside the compartment show a considerable increase and then decrease as the opening elevation moves up (Fig. 2) indicating the heat release rate inside the compartment changes. The flow structure changes significantly and temperature is not uniform especially at the region close to the opening as the opening moves up. The flame height increases firstly, reaches the maximum when the opening is located at approximately half height of the fire compartment, and subsequently decreases as the opening moves up. (Fig. 3).

(2) The normalized flame base height above the opening bottom decreases as the opening moves up (Figs. 5 and 6). The variation of the flame base location is caused by mixing of the inflow air during 
its movement downwards after it enters the compartment owing to its higher density relative to the gases in the compartment. The critical heat release rate for intermittent flame ejection (i.e. $50 \%$ probability) decreases as the opening moves up (Fig. 7).

(3) A new model for flame height to account for the effect of opening elevation, by taking into account physically the changes of the critical heat release rate for flame ejection, the flame base location and the horizontal momentum of the out flow at the opening (hence the characteristic length $\ell_{2}$ ), has been established (Fig. 8, Eq. 8).

This work presents a fundamental observation and understanding on the opening elevation effect on flame ejecting behavior through the opening of fire compartment. Regarding the difference in the interaction of inflow-outflow through the opening of various elevations, the flow structure and pattern is changed. This results in essentially illustrate the variations in flame base location, flame ejection behavior and flame height, as a basic understanding for this topic.

\section{Acknowledgements}

This work was supported by National Natural Science Foundation of China under Grant No.51706212.

\section{References}

[1] S. Yokoi, Study on the Prevention of fire spread caused by hot upward current, Japan, Report 34, Report of the Building Research Institute, 1960.

[2] L.G. Seigel, The projection of flames from burning buildings, Fire Techno. 5 (1) (1969) 43-51.

[3] P.H. Thomas, M. Law, The projection of flames from buildings on fire, Fire Prev. Sci. Techno. 10 (1972) 19-26.

[4] X.Q. Sun, L.H. Hu, W.K. Chow, Y. Xu, F. Li, A theoretical model to predict plume rise in shaft generated by growing compartment fire, Int. J. Heat Mass Trans. 54 (2011) 910-920. 
[5] K. Himoto, T. Tsuchihashi, Y. Tanaka, T. Tanaka, Modeling thermal behaviors of window flame ejected from a fire compartment, Fire Safety J. 44 (2009) 230-240.

[6] Y. Ohmiya, S. Yusa, J.I. Suzuki, K. Koshikawa, M.A. Delichatsios, Aerothermodynamics of fully involved enclosure fires having external flames, Fourth International Seminar Fire and Explosion Hazards (2003) 121-129.

[7] Y. Ohmiya, T. Tanaka, T. Wakamatsu, A room fire model for predicting fire spread by external flames, Fire Sci. Techno. 18 (1) (1998) 11-21.

[8] Y. Ohmiya, Y. Hori, K. Sagimori, T. Wakamatsu, Predictive method for properties of flame ejected from an opening incorporating excess fuel, Proceedings of the 4th Asia-Oceania Symposium on Fire Science Technology (2000) 375-386.

[9] L.H. Hu, F. Tang, M.A. Delichatsios, K.H. Lu, A mathematical model on lateral temperature profile of buoyant window spill plume from a compartment fire, Int. J. Heat Mass Trans. 56 (2013) 447-453.

[10]K. Himoto , T. Tsuchihashi , Y. Tanaka , T. Tanaka, Modeling the trajectory of window flames with regard to flow attachment to the adjacent wall, Fire Safety J. 44 (2009) 250-258.

[11]E.K. Asimakopoulou, D.I. Kolaitis, M.A. Founti, K. Chotzoglou, Characteristics of externally venting flames and their effect on the facade: a detailed experimental study, Fire Technol. 52 (2016) 2043-2069.

[12]E.K. Asimakopoulou, D.I. Kolaitis, M.A. Founti, Assessment of fire engineering design correlations used to describe the geometry and thermal characteristics of externally venting flames, Fire Technol. 53 (2017) 709-739.

[13]E.K. Asimakopoulou, D.I. Kolaitis, M.A. Founti, Geometrical characteristics of externally venting flames: assessment of fire engineering design correlations using medium-scale compartmentfacade fire tests, J. Loss Prevention Proc. 44 (2016) 780-790.

[14]W. Gao, N. Liu, M.A. Delichatsios, Fire spill plume from a compartment with dual symmetric openings under cross wind, Combust. Flame 167 (2016) 409-421. 
[15]K. Livkiss, S. Svensson, Bjarne Husted, P.V. Hees, Flame heights and heat transfer in facade system ventilation cavities, Fire Technol. 54 (2018) 689-713.

[16] Y. Hattori, K. Matsuyama, H. Suto, S. Okinaga, E. Onuma, Interaction of a pool fire in a compartment with negative pressure generated by mechanical ventilation, The Proceedings of 10th Asia-Oceania Symposium on Fire Science and Technology (2015) 89-96.

[17]S. Vilfayeau, N. Ren, Y. Wang, A. Trouvé, Numerical simulation of under-ventilated liquid-fueled compartment fires with flame extinction and thermally-driven fuel evaporation, Proc. Comb. Inst. 35 (2015) 2563-2571.

[18]Y.P. Lee, M.A. Delichatsios, G.W.H. Silcock, Heat fluxes and flame heights in facades from fires in enclosures of varying geometry, Proc. Comb. Inst. 31 (2) (2007) 2521-2528.

[19]Y.P. Lee, M.A. Delichatsios, Y. Ohmiya, The study for the physics of the outflow from the opening of a burning enclosure, Proceedings of the $5^{\text {th }}$ International Seminar on Fire and Explosion Hazards (2007) 381-392.

[20] Y.P. Lee, Heat fluxes and flame heights in external facade fires, $\mathrm{PhD}$ thesis, FireSERT, University of Ulster, United Kingdom, 2006.

[21]F. Tang, L.H. Hu, M.A. Delichatsios, K.H. Lu, W. Zhu, Experimental study on flame height and temperature profile of buoyant window spill plume from an under-ventilated compartment fire, Int. J. Heat Mass Trans. 55 (2012) 93-101.

[22]I. Oleszkiewicz, Heat transfer from a window fire plume to a building facade, HTD - Collected papers in Heat Transfer, (1989) vol. 123, Book No. H00526.

[23]J.I. Yamaguchi, T. Tanaka, Temperature profiles of window jet plume, Fire Sci. Techno. 24 (1) (2005) 17-38.

[24]L.H. Hu, K.H. Lu, F. Tang, M. Delichatsios, L.H. He, A global non-dimensional factor characterizing side wall constraint effect on facade flame entrainment and flame height from opening of compartment fires, Int. J. Heat Mass Trans. 75 (2014) 122-129.

[25]L.H. Hu, F. Tang, M.A. Delichatsios, Q. Wang, K.H. Lu, X.C. Zhang, Global behaviors of 
enclosure fire and facade flame heights in normal and reduced atmospheric pressures at two altitudes, Int. J. Heat Mass Trans. 56 (2013) 119-126.

[26]K.H. Lu, L.H. Hu, M.A. Delichatsios, F. Tang, Z.W. Qiu, L.H. He, Merging behavior of facade flames ejected from two windows of an under-ventilated compartment fire, Proc. Comb. Inst. 35 (2015) 2615-2622.

[27]L.H. Hu, S. Liu, L. Wu, Flame radiation feedback to fuel surface in medium ethanol and heptane pool fires with cross air flow, Combust. Flame 160 (2013) 295-306.

[28]L.H. Hu, S. Liu, Y. Xu, D. Li, A wind tunnel experimental study on burning rate enhancement behavior of gasoline pool fires by cross air flow, Combust. Flame 158 (2011) 586-591.

[29]N. Otsu, A threshold selection method from gray-level histogram, IEEE Trans. Sys. Man. Cyber. 9 (1979) 62-66.

[30]L.H. Hu, K.H. Lu, M.A. Delichatsios, L.H. He, F. Tang, An experimental investigation and statistical characterization of intermittent flame ejecting behavior of enclosure fires with an opening, Combust. Flame 159 (2012) 1178-1184.

[31]L.H. Hu, A review of physics and correlations of pool fire behaviour in wind and future challenges, Fire Safety J. 91 (2017) 41-55.

[32]B. Karlsson, J.G. Quintiere, Enclosure fire dynamics, CRC Press, 2000. 


\section{$\underline{\text { Figure Captions }}$}

Fig. 1 Experimental setup

Fig. 2 Gas temperature rise inside the fire compartment for different opening elevations

Fig. 3 Facade flame heights from the flame base level show to first increase then decrease with rising of the opening elevation

Fig. 4 An illustration of the flow pattern for different elevations of opening on the facade simulated by FDS (Compartment A)

Fig. 5 Flame base distance from the opening bottom does not change with the HRR but it changes with the elevation of the opening

Fig. 6 Normalized flame base distance for different opening elevation showing it decreases linearly with increasing of opening elevation

Fig. 7 The mean (i.e. $50 \%$ probability) HRR for flame ejection normalized by HRR inside the compartment at different opening elevations

Fig. 8 A new model for flame height to account for the effect of opening elevations 